\title{
Introduction: Frontline delivery of welfare-to-work in different European contexts
}

Rik van Berkel ${ }^{*}$,Flemming Larsen ${ }^{* *}$ and Dorte Caswell ${ }^{* *}$

*Utrecht University, The Netherlands; **Aalborg University, Denmark

\begin{abstract}
This themed issue contributes to European research on the role of front-line work in the implementation of welfare-to-work policies. A number of factors underline the relevance of such study. First, the focus on activating and disciplining the unemployed seen in many countries may on the surface look similar. However, a closer look at these policies and how they unfold in different contexts reveals many and interesting differences. While all contain a certain level of disciplining and coercive elements, they also to a varying degree contain elements that focus on the upgrading of skills, building human capital and providing other types of support in promoting labour-market participation. In turn, these policies contain both people processing and people changing technologies that are used for different aspects of policy delivery. In addition, policy developments have gradually expanded the client group of these policies, including more hard-to-place unemployed, thus making the client group more heterogeneous. Finally, we have seen a strong political belief in the positive effects of using punitive sanctions. Research supports this belief when it comes to clients with high employability and limited problems besides
\end{abstract}

Addresses for correspondence: Rik van Berkel, Utrecht University, Utrecht School of Governance, Bijlhouwerstraat 6, 3511 ZC Utrecht, The Netherlands; email: r.vanberkel@uu.nl. Flemming Larsen, Department of Political Science, Aalborg University, Fibigerstræde 1, Bygning: 9b, 9220 Aalborg $\varnothing$, Denmark; email: flemlar@dps.aau.dk. Dorte Caswell, Department of Sociology and Social Work, Campus Copenhagen, Aalborg University, Frederikskaj 10B, 2450 Copenhagen S, Denmark; email: caswell@socsci.aau.dk.

The articles that comprise this themed issue were first presented as papers at the 15th Annual ESPAnet Conference (Panel on Linking "Doing Policy" and "Policy Delivery": Frontline delivery of welfare-to-work policies in Europe), Lisbon, Portugal from 14-16 September 2017. 
unemployment, but the knowledge-base is rather shaky when it comes to the hard-to-place clients with substantial problems. Using punitive sanctions or other disciplining or coercive measures in frontline work has caused controversy and resistance. In order to qualify our understanding of welfare-to-work policies, we need to take a step closer to where these policies are translated into reality for the target group.

Keywords return to work, social security administration, social policy, Europe

\section{Introduction}

The idea for a themed issue on street-level bureaucracy in welfare-to-work policies came after the guest editors initiated and realized a stream at the ESPAnet conference in September 2017 in Lisbon, Portugal. The ESPAnet stream followed a recently published volume, Frontline delivery of welfare-to-work policies in Europe (van Berkel, et al., 2017). We were happily taken aback by the high level of interest from researchers from all over the world to participate in this stream. We received over 25 abstracts and selected 14 papers for presentation in four well-attended sessions that ran over two days. The overall high quality of the papers presented at the conference made the idea of proceeding with an issue containing research from scholars not included in the book the obvious next step - and the invitation from International Social Security Review to guest edit a themed issue based on the papers was therefore warmly welcomed. The growing interest in street-level bureaucracy research in recent years has been noticeable and substantial. Not only for the said ESPAnet conference, but also prior to this at the International Conference on Public Policy (Grenoble, France in 2013; Milan, Italy in 2015; and Singapore in 2017) and at the 2015 and 2017 Street-level Bureaucracy Research Conferences at Aalborg University in Copenhagen, Denmark.

While studies on the role of front-line work in the implementation of welfare-towork policies have been conducted in Australia and the United States since the 1990s, European interest in this type of study started in the first decade of this millennium. To contribute to European research in this field is an important aim for the guest editors of this issue. Why, then, is it relevant to study the frontline work that takes place in the implementation of activation and welfare-to-work policies?

First of all, the strong and not-so-new policy current focusing on activating and disciplining unemployed workers that has swept across most of the Western world 
may on the surface look similar. However, when we take a closer look at these policies, and how they unfold in different contexts, we find many and interesting differences. While these welfare-to-work policies all contain a certain level of disciplining and coercive elements, they also to a varying degree contain elements that focus on the upgrading of skills, building human capital and providing other types of support to promote labour-market participation. These opposing elements co-exist in the welfare-to-work policies and give room for variation in policy delivery at the frontline. Second, these policies contain both people processing and people changing technologies (Hasenfeld, 2010) that are used for different aspects of policy delivery. In addition, we have seen policy developments that have gradually expanded the client group of these policies, including the more hard-to-place unemployed, thus making the client group more heterogeneous. This has, in turn, made the selection of technologies and measures that frontline workers use for these clients more complicated. Finally, yet importantly, we have seen a strong political belief in the positive effects of using punitive sanctions. Research supports this belief when it comes to clients with high employability and limited problems besides unemployment, but the knowledge base is rather shaky when it comes to the hard-to-place clients with substantial problems. Using punitive sanctions or other disciplining or coercive measures in frontline work has caused controversy and resistance. To qualify our understanding of welfare-to-work policies, it is not sufficient to understand policy on paper. Instead, we need to take a step closer to where these policies are translated into reality for the target group. This process of translation should be understood not as an implementation failure, but rather as structured patterns that link to a myriad of contextual factors that play decisive roles in frontline work and thus for the clients in question.

Policy implementation is therefore to be considered as part of the policy-making process where street level bureaucrats acquire a role as policy-makers (Lipsky, 2010). Studies of formal policies can only provide a partial understanding of what policy looks like in practice and what policy does for the citizens for whom it is directed. Brodkin (2017) has called this the "missing middle" of policy analysis. Thus street-level bureaucrats are not only "agents of the state" acting in the role of policy implementers - they are also mediators of policies and politics. What street-level bureaucrats do in their everyday work on the frontlines of the welfare state depends on much more than their individual preferences and characteristics. Brodkin (1997) argues: "street-level bureaucrat do not do what they want, they do what they can" (p. 24). Discretion is inevitable in street-level work and street-level bureaucrats do have agency. One way to conceptualize this is that they have a certain "wiggle room" (Erickson, 2001). However, the room for discretionary decision-making is structured by context. We argue that an analytical model pointing out the following contextual elements will provide a 
conceptual framework for what kinds of contexts should be taken into consideration in order to better understand policy as it is realized on the frontline (Figure 1).

There is, in other words, a growing need for research that studies how frontline practices in activation are structured and shaped by the policy, governance, organizational and occupational contexts in which frontline workers do their work. Such type of knowledge is of immense importance to understand how frontline workers in street-level organizations deliver activation policies and services, in terms of the practical nature and content of activation services and processes. Besides the importance of gaining new knowledge on the treatment, involvement and participation of clients in activation processes, this also will enhance understanding of how frontline practices affect the intended and unintended outcomes of activation policies. The nature of this research needs to be empirically grounded and preferably comparative - where both internationally and nationally comparative studies may be very fruitful. The articles in this issue report on this type of research. As such they constitute an important contribution to the field; to date, there has been limited attention given to a comparative perspective in this research area. Fortunately, researchers in Europe and beyond who are interested in street-level bureaucracy research increasingly manage to connect with one another, as illustrated by our recent book (van Berkel et al., 2017), as well as the ESPAnet session from which this issue stems and our recurrent street-level bureaucracy conferences in Copenhagen. These types of collaboration are promising in terms of opening possibilities to develop more comparative analyses of street-level bureaucracy across contexts. Developing new empirical research with robust comparative research designs and

Figure 1. A contextualized approach of activation frontline work: An analytical model

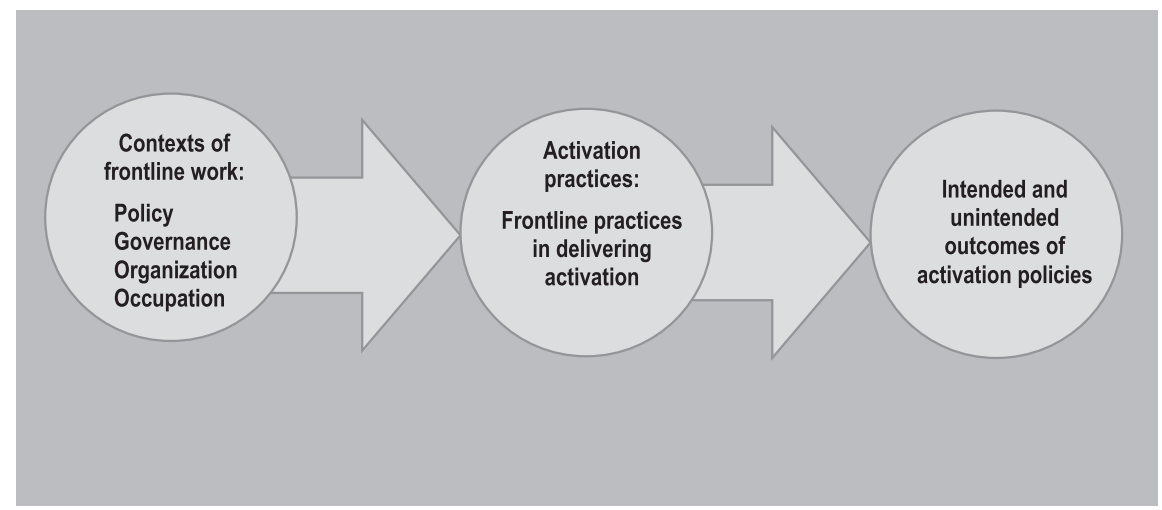

Source: Author. 
with high context sensitivity is very challenging, costly and time consuming. We hope to be able to accomplish this goal in time. One of the challenges for undertaking comparative studies is methodological. Many studies have approached the study of street-level bureaucracy from a qualitative or ethnographic position, often through case studies of different kinds. While these research designs have their limits in terms of empirical generalization and causality, they offer rich insights into the everyday practice of street-level work. Other studies have utilized administrative registers and different types of multi-level analysis. Studying street-level bureaucracy from a distance does however pose a danger to miss some of the finer grained negotiations, decisions or rationales that take place on the frontline. As argued recently by Zarka (2017) there are many good reasons for approaching this field of study with at least a degree of ethnographic sensitivity.

A comparative perspective can be fruitful even without an all-encompassing and methodologically ambitious starting point. One kind of comparative perspective is comparison between different national contexts. Looking across national contexts often permits to compare specific aspects of a policy, such as the organization of policy delivery, how the resources of frontline staff differ in terms of their qualifications, how much time frontline staff have for clients, or how different governance or control structures influence policy delivery at the frontline. The comparative perspective allows us to see differences and similarities, as well as to question elements that may be taken for granted in one national context, but where comparative research shows us how things may be less self-evident from an international point of view. Comparison sometimes takes a point of departure in categorizing, for instance, policy content (enabling or coercive) or assumptions about welfare state models. We argue that while these are obviously relevant factors to include in comparative analyses, they are not sufficient in terms of understanding the differences in welfare-to-work policy in practice. Comparative studies are however not limited to national comparisons, but can also be comparisons over time through longitudinal studies or comparisons of specific organizational models or across other types of contexts. In this issue we draw together five different articles all addressing welfare-to-work policy delivery in different European countries. As such, the point of this issue is essentially comparative. The contributions are not merely comparing across national contexts. Rather, a comparative perspective is applied in a variety of ways in the different contributions and can be read across the set of articles. One issue that surfaces across the articles is how administrative procedures and resources influence policy delivery. This contributes to further our understanding of how different contexts influence frontline work and thus plays an important role in the reality of policy delivery. Another issue is how the challenges to realizing successful welfare-to-work policies are sometimes overcome by innovative approaches that point towards a change in epistemic perspectives. Finally, yet 
importantly, the challenged - but conceivably changing - role of the client in policy delivery is addressed across the contributions.

\section{The set of articles}

The five articles that comprise this issue contribute to the growing comparative literature on frontline work in welfare-to-work policies. The first article by Eric Breit, Knut Fossestøl and Eirin Pedersen, "A knowledge hierarchy in labour and welfare services? Evidence-based and practice-based knowledge in frontline service innovation", focuses on recent developments in the Norwegian context of welfare-to-work. The article draws on a comparative case study of two local innovation projects conducted by the Norwegian Labour and Welfare Administration (NAV) in a four-year service innovation programme. The authors argue that although policy-makers and scholars have directed increasing attention towards collaborative innovation and knowledge development between frontline agencies and workers and other stakeholders such as citizens and researchers, empirical research has not focused on the (varying) assessment of collaborators regarding what knowledge would be "appropriate" to develop. Although the projects involved responded to the same call, they developed two very distinct types of knowledge; one dealt with practice-based knowledge and the other with evidence-based knowledge. The authors show that whereas the former knowledge type was contested and difficult to transform into practice, the latter involved few (if any) challenges and was implemented on a relatively large scale. These two projects point to the possible existence of a hierarchy of knowledge in labour and welfare services, where evidence-based forms of knowledge and methods are regarded as more legitimate and appropriate than forms of knowledge placed "lower" in the hierarchy. In the article, the reasons for and implications of this apparent hierarchy of knowledge for frontline work in labour and welfare services are discussed. The discussion of what kind of knowledge is relevant for developing welfare-to-work policy and practices is highly relevant in a broader comparative perspective.

In the second article, by Colin Lindsay, Sarah Pearson, Elaine Batty, Anne Marie Cullen and Will Eadson, "Co-production and social innovation in street-level employability services: Lessons from services with lone parents in Scotland", the argument is made that alternative governance approaches such as co-production and social innovation have the potential to be more successful than the typical United Kingdom approach. Compared to other European welfare-to-work contexts, the United Kingdom represents an exemplar liberal welfare state that has been characterized as in the vanguard of "work-first" activation - deploying high levels of compulsion and standardized employability services that seek to move people from welfare to work as quickly as possible. However, despite the 
extension of welfare conditionality to excluded groups such as lone parents, government-led, work-first employability programmes have often proved ineffective at assisting the most vulnerable to escape poverty or even to just progress into the labour market. This is the starting point for exploring an alternative approach to co-production. The authors draw on a large-scale qualitative study, with 90 interviews with lone parents and more than 100 interviews with delivery stakeholders and street-level workers. The study focused on local services targeting lone parents led by third sector-public sector partnerships in five localities in Scotland, and identified factors associated with positive social and employability outcomes. The research identifies a positive relation between programme governance and management that are defined by co-governance and collaborative partnership-working on the one hand and the co-production of street-level services that deliver benefits in terms of social innovation and employability on the other. The article concludes by identifying potential lessons for the governance and delivery of future services targeting vulnerable groups. In an international context where welfare-to-work has swept across many countries and where the effectiveness of this policy in terms of promoting the labour-market inclusion of the hard-to-place unemployed has been disappointing, the focus on innovation and co-production as a constructive way forward is highly relevant.

The third article, "Activating the most-disadvantaged youth in Switzerland: Administratively too risky, politically too costly?" by Delia Pisoni, is based upon a case study of a vocational education and training programme for disadvantaged youth in one Swiss canton. Pisoni finds that the programme did not reach the most-disadvantaged groups as intended. Instead, the findings show creaming practices as a coping strategy that enable frontline workers to satisfy strict assessment criteria. The author finds that for the majority of the organizations studied, access to public financing is vital, which makes reaching out to the most-disadvantaged target group youth too risky. The greater uncertainty of attaining the required success rate when working with the most disadvantaged youth risks undermining and even collapsing the programme's broad political support and thus might be seen as politically too costly. Instead, by focusing on the least-disadvantaged youth the probability of attaining the required success rate within the strict timeframe is increased. The logic behind this is mostly driven by a political and administrative logic of ensuring the programme's success to maintain legitimacy and funding for future similar programmes. The article illustrates well how the above-mentioned policy, governance and organizational contexts can frame frontline practices, thus underlining the need for researchers to be aware of these.

The fourth article, "Organizational governance of activation policy: Transparency as an organizational ideal in a Swedish welfare agency" by Katarina Hollertz, Kerstin 
Jacobsson and Ida Seing, investigates how the ideal of transparency is negotiated and enacted in the everyday actions of a welfare bureaucracy; namely, the Swedish Social Insurance Agency (Försäkringskassan - SSIA). Transparency is often used as a main argument for the governance logic of audit in a hierarchical manner. However, the article clearly demonstrates that transparency does not only relate to hierarchies in bureaucracies, but that the ideal of transparency is also negotiated more horizontally in the organization. Furthermore, the authors show how the ideal of transparency is enacted in the everyday work of the SSIA. The analysis shows how this transparency ideal comes to play a central role in the alignment of frontline staff with the normative regime of the agency. As an internalized ideal, transparency becomes a self-evident part of organizational life and, thus, of the everyday work of the caseworkers. However, the analysis further demonstrates how transparency is much less salient in relation to clients and the outside world. It is primarily a central part of internal organizational life. Although based upon a single case-study in a state-run agency, the article challenges some of the typical assumptions of how such a governance logic of vertical transparency frames frontline work, by showing that frontline workers use this more horizontally, without resistance and even with compliance. This acts to remind the field of research on street-level policy delivery of the need for caution when analysing how contexts interrelate with frontline practices, as well as of the need to be aware of organizational and, possibly, also occupational differences as important factors.

The fifth article, "Does individualized employment support deliver what is promised?: Findings from three European cities" by Deborah Rice, Vanesa Fuertes and Lara Monticelli, takes a closer look at governance conditions that facilitate or hamper the individualization of service delivery at street level. The article argues that since the inception of the European Employment Strategy in 1997, individualized employment support has been a key priority of the European Union and its Member States. Nevertheless, empirical research on the delivery of individualized services for the unemployed is still underdeveloped. The authors explore how local employment agencies in three European cities in Italy, Germany and the United Kingdom, tailor counselling and services to jobseekers' individual needs. The research design of this article is comparative across three national contexts, which enables the authors to contribute to a theoretical endeavour to outline under which conditions an effective individualization of counselling and services can be expected in street-level practice. The article confirms the crucial importance of (national or local) governance arrangements for street-level individualization practices and thus for clients. The authors find that limited service budgets and underdeveloped organizational interfaces with social service providers tend to constrain the substantive individualization of services in practice, which works to the disadvantage of vulnerable jobseekers. 
Individualized counselling is more widespread, at least for selected target groups. However, organizational capacities for offering individualized problem assessment and advice vary considerably across "worlds of individualization" in Europe.

We hope that this issue will show that to better understand policy as it is realized on the frontline, it is fruitful to apply a comparative and highly contextualised approach to welfare-to-work and its delivery. We welcome further comparative research in the years to come.

\section{Bibliography}

Berkel, R. van et al. 2017. Frontline delivery of welfare-to-work policies in Europe: Activating the unemployed. Abingdon, Routledge.

Brodkin, E. 1997. "Inside the welfare contract: Discretion and accountability in state welfare administration", in Social Service Review, in Vol. 71, No. 1.

Brodkin, E. 2017. "Street-level organizations and US workfare: Insights for policy and theory", in R. van Berkel et al. (eds), Frontline delivery of welfare-to-work policies in Europe: Activating the unemployed. Abingdon, Routledge.

Erickson, F. 2001. "Co-membership and wiggle room: some implications of the study of talk for the development of social theory", in N. Coupland, S. Sarangi and C. N. Candlin (eds), Sociolinguistics and social theory. London, Longman.

Hasenfeld, Y. 2010. "Organizational responses to social policy: The case of welfare reform", in Administration in Social Work, Vol. 34, No. 2.

Lipsky, M. 2010. Street-level bureaucracy. Dilemmas of the individual in public services. New York, NY, Russell Sage Foundation.

Zacka, B. 2017. When the state meets the street. Public service and moral agency. Cambridge, MA, Harvard University Press - Belknap Press. 